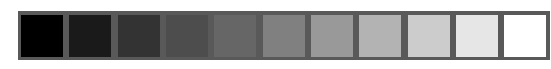

\title{
Conflitos pelo uso dos recursos naturais, direitos e processos de territorialização no rio Madeira (1880-1930)
}

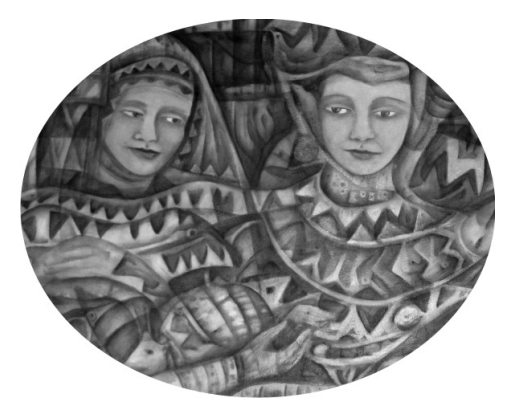

Davi Avelino Leal*

\section{Resumo}

O presente texto tem como objetivo discutir alguns aspectos relacionados aos conflitos por uso dos recursos naturais (borracha e castanha) na região do rio Madeira no final do século XIX e início do XX. O processo de fechamento do rio visando à demarcação de áreas para extração do látex por particulares encontrou forte resistência nos moradores que buscaram as mais variadas formas de protestar contra essa situação.

Palavras-chave: Processo de territorialização. Direitos. Conflitos.

\section{Abstract}

The present text has as its goal to argue some aspects related to conflicts for use of the natural resources (rubber and Brazil nuts) in the region of the Madeira river towards the end of the XIX century and beginning of the XX. The shutdown process of the river aiming at demarcating areas for the extraction of the latex by private concerns came across strong resistance by the inhabitants who sought for the most varied ways of protesting against such situation.

keywords: Process of territorialization. Rights. Conflicts.

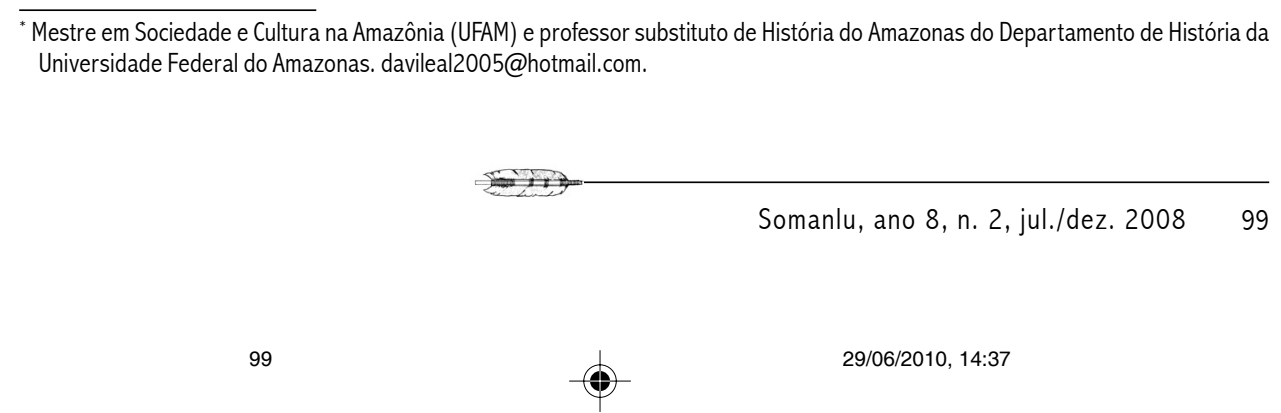

* Mestre em Sociedade e Cultura na Amazônia (UFAM) e professor substituto de História do Amazonas do Departamento de História da 
Impacientes com a situação e após uma longa e tensa conversa com os "humildes" moradores da localidade, os "lavradores" Gil Batista Braga, Cassiano Rodrigues de Souza e Joaquim Galdino Filho resolveram protestar e denunciar ao jornal Rio Madeira a demarcação ilegal, segundo eles, dos lugares"Parayba de Água Azul", "Santa Luzia" e "Bruno"; todos situados no lugar "Água Azul”, no município de Manicoré. O acusado por tal ato era José Francisco da Silva Santos.

Sensível a esse tipo de protesto o jornal publicou, no dia 22 de maio de 1918, a seguinte nota:

1) é porque no lugar "Parayba de Água Azul" terras devolutas, ocupadas pelo senhor José Francisco Silva, têm um terreno de cem metros de frente aproximadamente que o mesmo senhor vendeu a Francisco Pereira dos Santos pela quantia de cem mil réis; 2) porque o lugar "Santa Luzia" pertence à viúva e filhos de Gabriel Antonio Barbosa, que nele tem plantado 1.200 seringueiras, cafeeiros, roça de mandioca e várias áreas frutíferas; 3) porque nos lotes de terras de José Francisco da Silva pretende requerer tem as seguintes posses: seringueiras e castanheiras de Filismino Pereira com as plantações seguintes: seringueiras e árvores frutíferas; 4 ) porque a referida demarcação, o senhor Francisco dos Santos quer apossar-se de um castanhal a que sem direito algum já impõe; 5) porque vários moradores deste lugar têm estradas de seringueiras [itaúba] de que tiram o preciso para manter-se e que com a proteção do senhor Jose Francisco da Silva, terão os maiores prejuízos possíveis (Rio Madeira, Manicoré, 22 de maio de 1918).

Com base nessas denúncias, os moradores encerram a nota dizendo que vão continuar lutando por seus direitos e denunciando abusos de poder contra o "povo" e que eles estão prontos para fazer protestos de forma judicial.

Da mesma forma, "poderosos" proprietários de terras no rio Madeira recorrem ao jornal para também protestar contra os "simples" trabalhadores que impedem o processo de demarcação de novas áreas, alegando atos de violência desses "lavradores":

100 Somanlu, ano 8, n. 2, jul./dez. 2008 

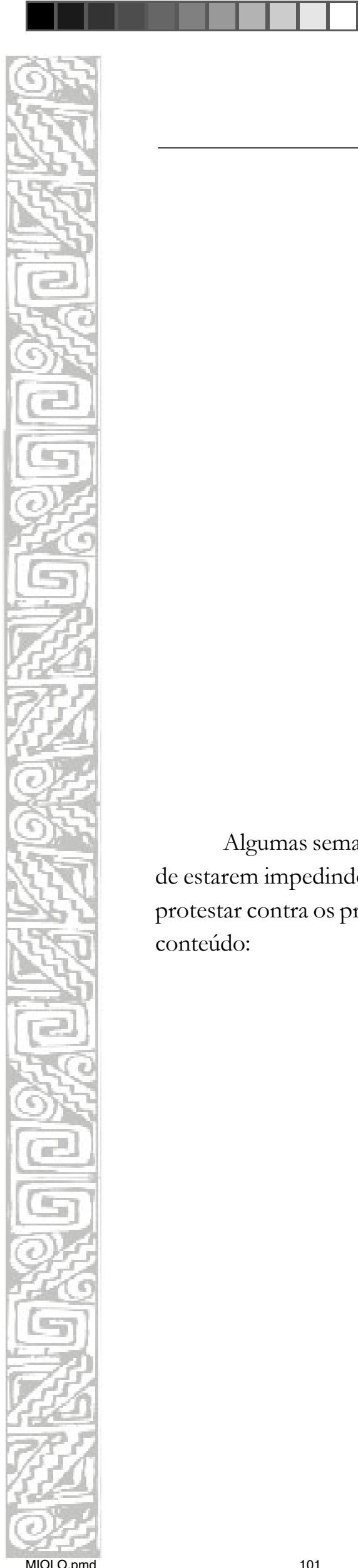
conteúdo:

Davi Avelino Leal

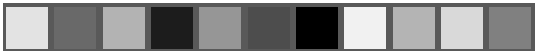

Já proibiram qualquer demarcação - alguns moradores do rio Mariepaua no intuito de assenhorasem dos castanhais daquele rio armaram-se de rifle e ameaçam de morte a qualquer pessoa que pretender demarcar castanhais no trecho compreendido entre o lugar Boa Vista e a foz do mesmo rio. Os valentes atravessaram a mão armada na frente dos aludidos castanhais e proíbem a qualquer comerciante ou castanheiros de entrar nos castanhais para fazer colheita. O sr. Raimundo Pereira Brasil, que demarcou no Mariepaua o lugar Boa Vista, está ameaçado de não tirar castanha ali no fabrico vindouro, caso insista pagará com a vida a tentativa. Apoiados no 44, proíbem os profissionais de correr as linhas de demarcação. São os principais cabeças desse movimento Laurentino Alves, João Dias, Ângelo das Chagas, Antonio Serafim e outros nomes. Somos informados também que Ângelo das Chagas, já tem em armas cinco homens para impedir a demarcação que o sr. Carlos Lindoso pretende fazer no lugar São Sebastião, daquele rio, neste município. Os prejudicados pedem providencias contra audaciosa atitude daqueles inimigos da ordem (O Rio Madeira, domingo, 26 de maio de 1918).

Algumas semanas depois, os lavradores acusados pelos donos de castanhais de estarem impedindo a demarcação das terras vão ao mesmo jornal se defender e protestar contra os proprietários. A nota de protesto dos lavradores tem o seguinte

Nós, abaixo assinado, moradores e lavradores no rio Mariepaua, percorrendo a leitura deste conjurado e respeitado jornal de 26 de maio p.f., deparamos com um artigo que diz estarmos de mãos de 44 para impedir a colheita dos produtos em castanhais existentes nos fundos dos terrenos que ocupamos nos serviços da lavoura, isto não deixa de ser um conto do vigário, escrito ou informado por indivíduos cuja vida não passa de uma sucessão de crimes e perversidades, julgando com as suas caluniosas informações venha alcançar tudo ao contento dos seus desejos. Apelamos para as autoridades deste rio, que com sua franqueza atestem qual tem sido o nosso modo de proceder perante as perseguições que temos sofrido, perseguições estas que têm sido movidas por mantenedores de abusos inqualificáveis, que se tem reproduzidos por diversos moradores deste rio. Porém para repelir

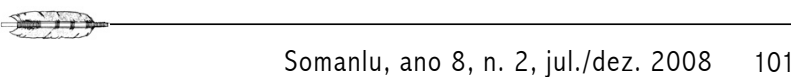


semelhantes abusos temos armas de superior calibre que é justamente a justiça distribuída pelo benemérito Dr. Alcântara Bacellar, atual governador de Estado que não trepidará em prestar-nos o seu valoroso auxilio (O Rio Madeira, Manicoré, 23 de junho de 1918).

O documento de protesto foi assinado pelos lavradores Laurentino Alves de Souza, Ângelo Estevam das Chagas - vulgo Cabeça de Fósforo -, João Dias Pinheiro, Antoni Alves de Souza e Luiz Antonio Gomes Pereira. Sua nota, denunciando a ação espoliativa, foi respondida na mesma edição pelo representante da força policial do lugar.

O subdelegado, Matias Brasil Junior, se pronunciou com relação ao caso dizendo:

Atesto sob o cargo que ocupo, independente de qualquer pedido que é falsa a informação que foi publicada no jornal "O Rio Madeira" de 26 de maio findo. Pois eu como autoridade percorro este rio e relaciono-me com o acusado Laurentino Alves de Souza e outros, e nada do que consta no artigo Mariepaua em foco existe, o que afirmo que tais coisas não passam de embustes feitos por bajuladores também afirmo que estes homens estão sendo injustamente perseguidos e prejudicados em suas lavouras devidos a demarcação levantadas no rio Mariepaua. É justamente o que afirmo sob minha palavra de honra e que os acusados podem fazer deste o uso que lhe convier (O Rio Madeira, Manicoré, 23 de junho de 1918).

Os trabalhadores acabaram conseguindo o apoio do subdelegado da área. Embora não conheçamos a relação de forças do momento, é interessante observar que a luta por recursos naturais se tornou uma questão bem explosiva na época. $\mathrm{O}$ caso acima mencionado marcou uma vitória, ainda que parcial, dos lavradores contra o processo de demarcação de terras que os expulsava de castanhais "tradicionalmente" utilizados.

Partindo dessas notas iniciais, podemos levantar algumas questões que articulam os conflitos por recursos naturais (estradas de seringa e castanha somente), uma relativa confiança no direito e os novos processos de territorialização no rio Madeira do final do século XIX e início do século XX.

102 Somanlu, ano 8, n. 2, jul./dez. 2008 


\section{Processo de territorialização do rio Madeira e a questão da terra (1880-1930)}

Desde meados do século XVIII, o rio Madeira passa a ser considerado como lugar estratégico, pois interligava economicamente o centro ao norte da colônia portuguesa. Para Alexandre Rodrigues Ferreira, o rio Madeira também era alvo de investidas comerciais que visavam à coleta das "drogas do sertão" e do apresamento da mão-deobra indígena. Segundo Alexandre Rodrigues Ferreira,

Por via da extração das drogas do sertão, e das manufaturas das manteigas e de peixes secos, a que se destinam os cabos das canoas do negócio das povoações do Pará; se bem que estes por semelhante motivo nunca passarão além da praia de Tamanduaçú, [...] Achando todos eles ou nas suas margens, ou as suas ilhas cada hum o negócio a que se destina: ou o cacau, ou a salsa, ou o cravo, ou a casca preciosa, a copaíba. Outros se entretem pelas praias com a fartura de manteigas de ovos, e das banhas das tartarugas, e das dos peixes bois, outros finalmente com a pesca, e com a salga do peixe para as provisões públicas e particulares (FERREIRA, 1949, p. 372).

Se as "drogas do sertão" eram cobiçadas pelos comerciantes portugueses, o fato que mais aglutinou esforços reais e particulares foi com relação à mão-de-obra. O mesmo Alexandre Ferreira nos diz que

quanto, porém aos gentios, cuidasse muito a promover o estabelecimento das aldeias, e a civilização dos índios, porque nestes dois pontos consistia o principal interesse do Estado e a eles se dirigiam os principais objetos de ordem de S. Majestade (FERREIRA, 1949, p. 370).

A segunda metade do século XIX é marcada por um novo processo de territorialização no Madeira. O interesse estatal se faz cada vez mais presente, pois a demanda de borracha, imposta pelo mercado internacional, mobiliza interesses públicos e privados para a área.

Gostaríamos de abrir um parêntese para explicitarmos que o que estamos chamando de processo de territorialização se refere à proposta formulada por João Pacheco de Oliveira, ou seja a territorialização implica: 
“1) a criação de uma nova unidade sócio-cultural mediante o estabelecimento de uma identidade étnica diferenciadora; 2) a constituição de mecanismos políticos especializados; a redefinição do controle social sobre os recursos ambientais; 3) a reelaboração da cultura e da relação com o passado" (OLIVEIRA, 1998, p. 55).

As "evidências" indicam que, a partir da segunda metade do século XIX, novas forças de transformação se voltavam para o rio Madeira. A abertura da Ferrovia Madeira-Mamoré (FOOT HARDMAN, 2005), o aumento das correrias de índios (VIEIRA, 2004) e o reforço do aparato policial (LEAL, 2007) sugerem que o Estado provincial se voltou com mais interesse para a área.

O aumento das exportações de borracha desencadeou o interesse na demarcação de terras para exploração de estradas da goma elástica, assim como despertou o interesse público para a regularização das áreas. A cobiça não era sobre a terra em si, mas sobre a produtividade de terras que tivessem borracha. Segundo Euclides da Cunha,

A unidade não é o metro - é a seringueira; e como em geral 100 árvores desigualmente intervaladas, constituem uma "estrada", compreende-se para logo todas as disparidades de forma e dimensões do singularíssimo padrão que é, não obstante, o único afeiçoado à natureza dos trabalhos (CUNHA, 2003, p. 335).

Deste modo, o processo de extração do látex se reproduz de forma dispersa na floresta. O seringueiro, com uma estrada apenas, caminha em média seis quilômetros por dia. Essa característica nos ajuda a pensar a extensão dos seringais.

De outro, a partir de 1870, podemos acompanhar, através dos Relatórios de Presidente de Província, o movimento de concessões de terras em toda a Província do Amazonas. Das 141 concessões feitas no ano (1870), as maiores foram nas cercanias da capital (31 concessões) e no rio Madeira (63 concessões). O objetivo dessas concessões era evitar o conflito entre seringalistas, que visavam expandir os domínios dos seringais. Segundo o relatório,

Vae-se desenvolvendo o desejo de possuir terras para a cultura, e para a industria extrativa, pela ciência tem adquirido, de

104 Somanlu, ano 8, n. 2, jul./dez. 2008 

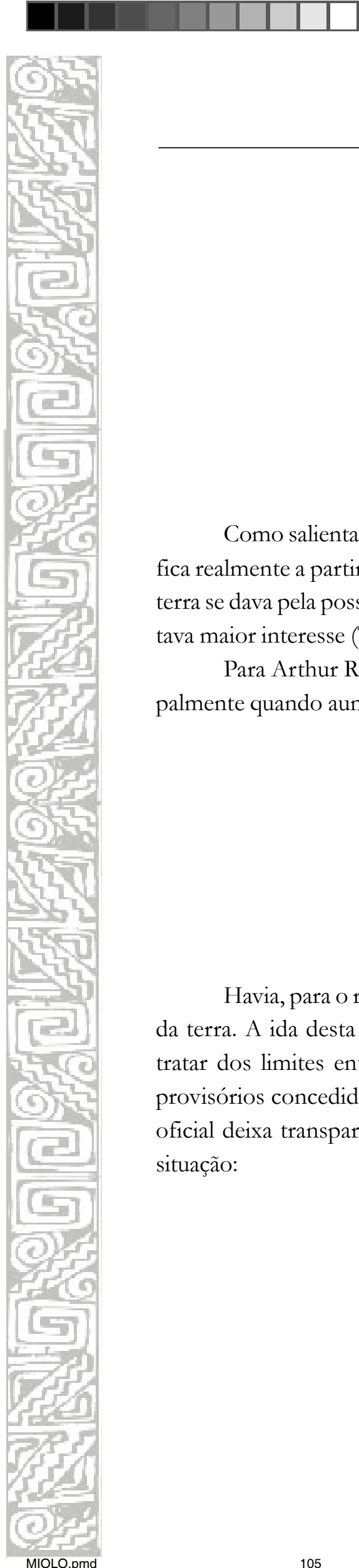
situação:

Davi Avelino Leal

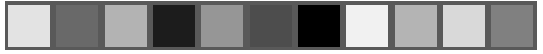

que nenhum direito tem eles à terra de que se acham de posse por meios contrários a lei. Muitos desses intrusos, com manifesto abuso de confiança, e infração dos preceitos da lei n. 601, depois de se haverem utilizado dos frutos espontâneos, vão, a título de descobridores, alienando estrada de seringas, que não são outra coisa mais do que bens nacionais. O governo imperial, tendo sido informado dessa prática abusiva, procura obstar a usurpação que assim se faz a fazenda nacional (RPP, 1870, p. 38, v. 15).

Como salienta Carlos Teixeira, a situação fundiária na Amazônia só se modifica realmente a partir de 1870, com a corrida para os seringais. Até então, o uso da terra se dava pela posse e, visto que a terra era abundante, naturalmente não despertava maior interesse (TEIXEIRA, 1980).

Para Arthur Reis, esse processo foi marcado por intensos conflitos, principalmente quando aumentavam as dificuldades para constituir novas posses.

O empossamento não se procedia sempre com serenidade, com mansidão. O choque entre seringueiros constituía, quando a facilidade de ocupação começou a diminuir, pelo menos aparentemente, páginas do 'rush'. Os assaltos aos seringais novos, na disputa da propriedade, eram constantes. E com assaltos, as perdas de vida nas lutas travadas (REIS, 1977, p. 141).

Havia, para o rio Madeira, uma comissão específica só para tratar da questão da terra. A ida desta comissão ao Madeira no ano de 1874 tinha como objetivo tratar dos limites entre os municípios, além de fiscalizar a situação dos títulos provisórios concedidos em 1869 e que teriam validade de 10 anos. O documento oficial deixa transparecer o pouco interesse dos donos de terra em regularizar a

Os possuidores de terras concedidas por aqueles títulos, livres assim das condições mais essenciais com que a lei facultou a concessão, com o fim de promover e animar o desenvolvimento da agricultura e da criação de gado, entregaram-se exclusivamente a industria extrativa, e não se apressam em satisfazer as condições que lhe impõem os títulos

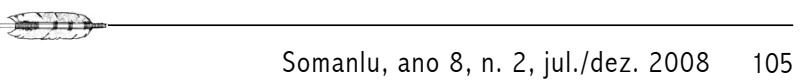


de que estão ou não de posse, fundados no largo prazo que lhe foi marcado, até o fim do qual lhe julgam poder usufruir os terrenos que ocupam sem ônus nem qualidade alguma. A mesma natureza da industria a que se entregam não os torna muito desejosos de ver demarcadas as suas concessões, por quanto não admitindo limitação de área a exploração da única espécie vegetal a qual estão ligados - a seringueira eles querem a faculdade de estenderem os limites de suas concessões até onde os exijam a necessidade de exploração e o permitam os interesses dos concessionários, posseiros e ocupantes vizinhos, que por sua parte tratam de alargar o mais possível os seus domínios. Daí a colisão de interesses, e as conseqüências questões de terras que constantemente surgem no rio Madeira (RPP, 1874, p. 155, v.17).

Visando evitar conflitos ao poder público, havia interesse para que as terras fossem regulamentadas. O relatório de 1874 anexou um documento dedicado, em sua totalidade, à questão de terra no rio Madeira. $\mathrm{O}$ que chama atenção são os vários relatórios de Presidente de Província, pois, quando tratam da questão de terras, geralmente se referem ao Madeira. Seguindo a leitura do citado relatório, podemos perceber que a grande maioria das terras estavam ilegais ou com a concessão prestes a vencer. Com exceção de algumas posses já legitimadas, o que se via, de forma geral, era a lei de terras ser descumprida, como infere a citação:

Quanto as demais, que formam a quase totalidade das posses, estão quase completamente fora da lei de terras, e não se fundam geralmente senão na ocupação primária, de data posterior a referida lei, ou efêmeros títulos de compra feitos pelos atuais ocupantes, não raras vezes por somas consideráveis, aos que primeiro se estabeleceram nos lugares e ali exerceram a industria extrativa, sem entretanto possuírem titulo algum legitimo que os autorizasse a vender terras que eram e são devolutas, e como tais pertencentes ao Estado.

A exploração dos seringais, em que abundam os terrenos úmidos e baixos do Madeira, alem dos nacionais que para ali concorrem a ocupar os terrenos pelo modo por que fica dito, tem também atraído a cidadãos bolivianos, que ali se estabelecem do mesmo modo por que vem fazerem-nos os naturais do país, isto é, por ocupação das terras ainda não exploradas ou por compra das que já começarão a sê-lo. Cumpre notar

106 Somanlu, ano 8, n. 2, jul./dez. 2008 

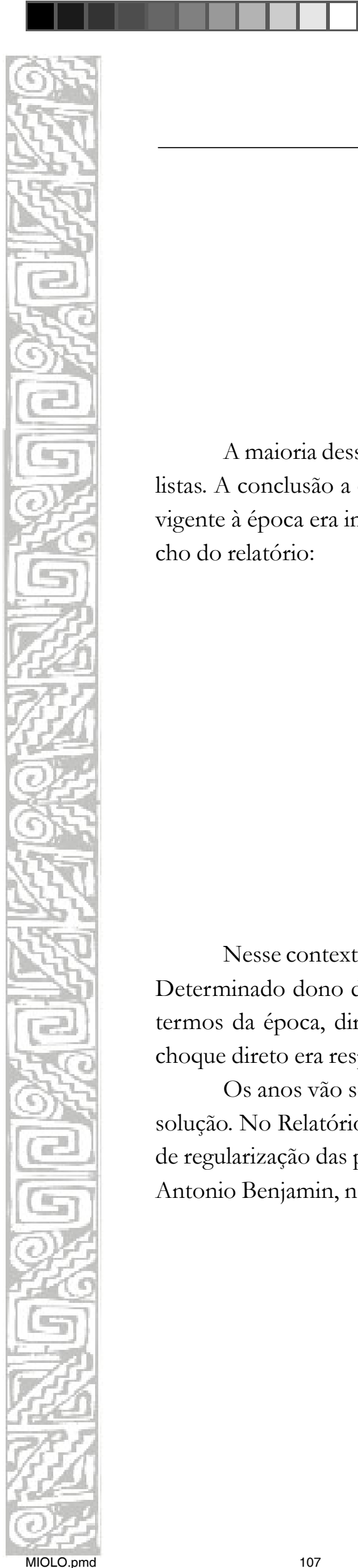
cho do relatório:

Davi Avelino Leal

que muitos desses estabelecimentos existem já no rio Madeira, especialmente na cachoeira de Santo Antonio, abaixo da mesma cachoeira, e alguns deles importantes pelo número de índios da mesma nacionalidade que empregam na extração e preparação de borracha, e mesmo em alguma cultura (RPP, 1874, p. 155, v. 17).

A maioria dessas terras estavam temporariamente sob domínios de seringalistas. A conclusão a que chegou o chefe da comissão é a de que o quadro de leis vigente à época era impróprio para tratar da questão, como mostra o seguinte tre-

Tal era o estado territorial do rio Madeira. Há ali interesses de suma importância a atender: interesses do Estado e interesses de particulares. As condições anormais a que se acha a propriedade territorial naquela região não podem ser convenientemente atingidas pelas leis gerais que regulam esta matéria e a legislação nunca poderá ser efetuada sem o auxilio de medidas serialmente refletidas e convenientemente aplicadas. E o que reconheceu o chefe da comissão desde os primeiros trabalhos empreendidos naquele rio, e o que por ele tem sido exposto ao governo nas informações que lhe tem dado (RPP, 1874, p. 156, v. 17).

Nesse contexto, o conflito entre seringalistas tornou-se um fato corriqueiro. Determinado dono de seringal, ou patrão, reunia os seus fregueses e, usando os termos da época, dirigiam-se para "tomar" as terras de outro seringalista. Esse choque direto era responsável por muitos mortos e feridos nos seringais.

Os anos vão se passando e os problemas relativos às terras continuam sem solução. No Relatório da Comissão de Terras, de 1877, estão os mesmos pedidos de regularização das posses contidos no relatório de 1874. O relator, Dr. Feliciano Antonio Benjamin, nos diz:

Nos lugares que percorri da província, fui solícito em aconselhar a todos que tinham seus estabelecimentos em terrenos, cuja a posse não estava legalizada, que tratassem de regularizar o seu domínio e fazer demarcar os terrenos, que ocupavam, o que o decreto de 3 de junho de 1874 já tornava fácil, até certo ponto, afim de terem o direito de se oporem a 
qualquer invasão que de outro modo não poderiam embaraçar, senão pela força ou por meios contrários a lei.

Sobretudo nos rios Madeira e Purus, que são de uma riqueza incalculáveis, acha-se estabelecida uma grande população em terrenos que nunca compraram e de que se vão apoderando contra as expressas disposições das leis vigentes, e o que é pior e que muitas vezes abandonam depois de haver arruinado as suas preciosas árvores para irem fazer o mesmo em outro lugar (RPP, 1877 , p. 43, v. 20).

Alguns anos mais tarde, a disputa por terras no Madeira continua a ser um assunto da maior importância. Um outro caso, vinculado pelo mesmo jornal, retrata o acerto de contas entre fregueses de um seringal com fregueses de outro. Segundo a nota do jornal, eram fregueses em defesa das estradas dos seus respectivos patrões:

\begin{abstract}
A Bala - consta-nos que diversos indivíduos que se diziam fregueses do sr. Laurindo Trindade, no rio Machado, resolveram liquidar a questão que neste fôro tem aquele cidadão com o sr. Accacio Ferreira do Valle, e dirigiram-se aos seringais que este obteve por escrituras de um acordo e ali intimaram, a bala, aos fregueses do sr. Accacio para desocuparem as estradas.

Tendo havido resistência, em vista de que as estradas são situadas nas serras que couberam ao sr. Accacio por força de um contrato lavrado em notas de um Tabelião, em Manaus, sucedeu sair um dos agressores com um ferimento. Lamentamos que esse fato tenha dado com a ação da justiça da pólvora, quando aqui próximo há a justiça da lei (HUMAYTHAENSE, 30/06/1907, n. 34, ano XVI).
\end{abstract}

As disputas pelas estradas de borracha e de castanha não estavam relacionadas apenas aos patrões. O marcante desse processo reside em indicar um grande fechamento no rio Madeira. As pessoas comuns, que outrora tinham acesso à terra, e que podiam trabalhar nas estradas colhendo castanha e extraindo borracha, são agora sistematicamente proibidas de realizar tal atividade.

A demarcação de áreas "comuns" gerou, por parte destes trabalhadores, uma série de protestos nos jornais da época, e vários casos foram parar nos tribunais locais e estaduais.

108 Somanlu, ano 8, n. 2, jul./dez. 2008 


\section{Conflitos no judiciário e a disputa pelos seringais}

Uma das mais longas brigas na justiça por posse de seringais se deu com a família Chaves, de 1918 até o final da década de 1930. Esse litígio envolveu várias gerações dos Chaves, que entraram na justiça contra os espólios da firma aviadora B. Levy \& Cia.

No ano de 1918, Antonio Chaves entrou com uma apelação comercial contra B. Levy \& Cia, pois estes últimos reivindicavam a posse de seus seringais e castanhais no município de Humaitá. No caso específico, a propriedade estava dividida entre a família de Antônio Chaves e a família do senhor Hermínio Cuellar.

A família de Hermínio Cuellar hipotecou doze seringais aos B. Levy \& Cia; no entanto, esta firma queria incluir os castanhais, a casa de moradia, barracas e mais propriedades pertencentes a Antônio Chaves.

No presente caso, a justiça acatou o pedido de Antônio Chaves por entender que os castanhais e outros bens alegados pelo apelante constituíam propriedade distinta e separada da que foi hipotecada por Hermínio Cuellar (LDJJA, 1918, p. 306) ${ }^{1}$.

Três anos depois, em 1921, a firma faz uma nova investida contra os seringais e castanhais da família Chaves. Num pedido de agravo à justiça de Humaitá, a firma aviadora exige que João Evangelista Chaves, Adélia Lideman Chaves e Antonio Chaves Filho, parentes de Antonio Chaves, entreguem os lotes de terra "Barraca do Meio, Repartição, Reverso, Bom Retiro, São Joaquim, Mudança, Fortaleza e Sorveira”, todos situados em Humaitá e que são ricos em castanhais.

Os filhos de Antonio Chaves defendem-se dizendo que possuem aqueles seringais e castanhais por herança e por exploração feita e que tiveram reconhecimento do Governo do Estado através da demarcação do engenheiro Camillo Lellis Monteiro (LDJJA, 1921, p. 316).

A firma B. Levy \& Cia. alegou que o engenheiro Erasmo Gnone também trabalhou demarcando essas terras e que elas faziam parte da empresa seringalista. O que se seguiu foi um conflito de jurisdição, pois a família Chaves solicitou do juiz municipal de Humaitá uma interdição proibindo o esbulho da firma aviadora. No entanto, o caso foi encaminhado para a cidade de Manaus, contando com a interferência de vários juízes da capital.

Independentemente do resultado do agravo, o documento revela como os sujeitos diferenciados recorreram a instâncias também diferentes, exigindo direitos que

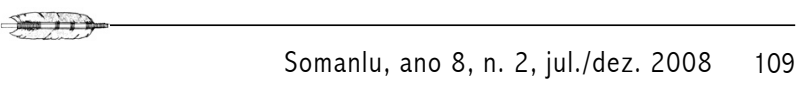


acreditavam possuir. Parece-nos que a manobra de transferir o conflito jurídico para Manaus poderia favorecer diretamente a citada firma aviadora; porém, nem sempre. E parece ter sido esse, o presente caso: aquele que apresenta maior poder econômico obtém somente resultados favoráveis.

Em 1926, Roman Chavez e sua mulher Rachel Ortiz Chavez entraram na justiça com o pedido de agravo contra o esbulho de dois seringais em Manicoré. Os lugares Sant'Ana e Suspiro foram tomados pela firma B. Levy \& Cia.

Roman Chavez, filho de Antonio Chavez e, possivelmente, parente de Ricardo Chavez, pois, segundo Waren Dean, este último "estivera envolvido no comércio de borracha como "patrão", isto é, um intermediário que dava adiantamentos a seringueiros, descera o rio Madeira com duzentos índios da tribo Moxo e se estabelecera num lugar chamado Carapanatuba" (DEAN,1989, p. 40). Chavez pedia na justiça a restituição de posse, pois alegava abuso por parte da firma citada. No entanto, o pedido feito à justiça era todo tempo negado por falta de provas do esbulho. Os B. Levy \& Cia. ainda alegavam que a família de Roman Chavez usara da violência quando da transferência da posse dos referidos seringais. Segundo o documento, foi necessário o uso da força policial para fazer com que a firma tomasse posse dos seringais.

Alguns anos mais tarde, o embate judicial ainda se arrastava. No documento, longo e confuso, de 1928, a família Chavez alega que o lugar denominado de Carapanatuba (comarca de Manicoré) não havia sido incluído na hipoteca feita de seus bens poucos anos antes.

Devendo à firma B. Levy \& Cia. a quantia de 136:000\$000, os Chavez haviam dado, para quitação da dívida, seus seringais com todas as plantações e benfeitorias. A dação dos bens correspondia aos imóveis: lugar SantAnna, à margem esquerda do rio Madeira, município de Manicoré, com uma área de 13.775.00 metros quadrados e um perímetro de 22.310 metros lineares, limitando-se ao sul, com a margem esquerda do rio Madeira, com 4.800 metros de extensão do primeiro marco de "Carará" que é o segundo de SantAnna ao primeiro de SantAnna, a este, com terras do Carará de Antonio Chavez, com 7.240 metros de linhas quadradas, do segundo marco ao terceiro SantAnna e do primeiro ao quarto Carará, a oeste, com terras devolutas, com 6.470 metros. Este lugar possuía seringais, plantações e outras benfeitorias achando-se as terras registradas segundo título definitivo expedido pelo governador do Estado do Amazonas em 13 de dezembro de 1893 (LDJJA, 1928, p. 510).

110 Somanlu, ano 8, n. 2, jul./dez. 2008 
O segundo seringal hipotecado chamava-se Suspiro. Situado no mesmo município, possuía uma área de 17.257.500 metros quadrados e um perímetro de 28.970 metros lineares, a começar do segundo marco, que é o terceiro do lote de SantAnna e o quarto de Carará. Em Suspiro havia seringais, plantações e outras benfeitorias registradas pelo governador do Estado do Amazonas, em 31 de dezembro de 1893 (LDJJA, 1928, p. 511).

A "dação" dos imóveis à firma B. Levy \& Cia foi realizada em 24 de novembro de 1925, sendo que a mesma permitira a Roman Chavez permanecer trabalhando no lugar até 30 de dezembro daquele ano, com prazo máximo para eles se retirarem da localidade se estendendo até o dia 25 de fevereiro de 1926. Faltando dez dias para terminar o prazo, a firma B. Levy \& Cia entrou na justiça contra a família de Roman Chavez alegando espoliação. Segundo a firma aviadora, a família Chavez estaria se negando a deixar o lugar, quebrando o combinado (LDJJA, 1928, p. 512).

Os oficiais de justiça do município de Manicoré, diante do mandado expedido pelo juiz daquela localidade, foram, juntamente com força armada, restituir a posse da empresa seringalista. Roman Chavez e sua mulher alegaram ao juiz que não havia motivo de tal ação, pois eles não se opunham a entregar os bens, apenas reivindicavam o lugar Carapanatuba, que não estava na lista de "dação".

O parecer do juiz do Supremo Tribunal foi de que a firma B. Levy \& Cia não poderia ter dado entrada no pedido de esbulho sem oferecer provas, já que ainda não se completaram os 90 dias cedidos a Roman e Rachel Chavez residirem em SantAnna. Ainda, segundo o juiz, os oficiais de justiça de Manicoré agiram de má fé e criminalidade, sendo culpado de esbulho violento e com força armada o juiz de Manicoré por tirar a posse do verdadeiro dono, a família Chavez, que foi forçada a abandonar o lugar onde residia.

Para o juiz do Supremo, o esbulho alegado e não comprovado era uma farsa para se apropriar do lugar Carapanatuba, que não fora dado em pagamento. A violência do esbulho fora cometida pela firma aviadora, que arquitetou um plano para produzir os despejos dos Chavez e locupletar-se de bens que não entraram na "dação".

O juiz convocou as testemunhas para falarem sobre o caso em litígio. Das três pessoas convocadas, duas eram empregadas da prefeitura de Manicoré e disseram que desconheciam o esbulho alegado pela firma aviadora. A terceira testemunha, que morava longe dali e fora convocada de última hora, alegou que os B. Levy não haviam cometido violência alguma (LDJJA, 1928, p. 516).

Somanlu, ano 8, n. 2, jul./dez. 2008111 
Mais uma vez, a declaração das testemunhas desautorizava a atitude dos oficiais de justiça Antonio Olympio Ribeiro e Roque da Silva Pinto, que foram severamente repreendidos pelo juiz do Supremo Tribunal, assim como o juiz de Manicoré que parecia não ter a prática de julgar, pois não atentou para o prazo de vencimento do acordo para a saída dos Chavez, que ainda não havia vencido, e para a verdadeira alegação de esbulho por parte dos B. Levy (LDJJA, 1928, p. 518).

O posicionamento do juiz do Supremo Tribunal foi a favor de Roman Chavez e sua esposa Rachel Chávez; a firma B. Levy, não conformada com a sentença, recorreu da decisão do juiz. Casos como esses nos ajudam a pensar como poderosas empresas aviadoras amargaram derrotas no poder judiciário. Claro que a família Chavez era uma das mais poderosas da região; embora tenham entrado em decadência com a crise da economia gomífera, ainda tinham posses (seringais, plantações e benfeitorias) e sustentavam certo prestígio (se a indicação de Dean estiver correta) na cidade de Manicoré.

Podemos perceber, a partir desses casos, que a principal forma encontrada pela firma B. Levy \& Cia para adquirir seringais foi através do pagamento de dívidas, dos antigos seringalistas, contraídas durante os anos de crise de extração do látex. Se atentarmos para o quadro de seringais da firma, perceberemos que a maioria dos 309 seringais foi adquirida na década de 1920, ou seja, num período de retração da economia gumífera.

Um outro dado interessante é a indicação de que nos lugares em litígio havia não só seringais, mas também plantações. A historiografia aponta, de forma geral, que a partir da crise de 1912, e principalmente na década de 1920, inicia-se a formação de um "campesinato" na Amazônia. Os seringueiros são obrigados, pelas complicadas condições de vida, a cultivarem uma roça para diminuir a dependência com as casas aviadoras (DEAN, 1989, p. 79; VELHO, 1979, p. 193).

Esse caso nos ajuda a pensar também nas disputas travadas no campo jurídico a partir das reflexões do historiador inglês Edward Thompson. Nas conclusões de Senhores e Caçadores, há um tópico esclarecedor, intitulado o dominio da lei, onde o autor aponta a lei como uma arena de conflitos. Para Thompson:

a lei não foi apenas imposta de cima sobre os homens: tem sido um meio onde outros conflitos sociais tem se travado. Em parte, as próprias relações de produção só têm sentido nos termos de suas definições perante a lei: o servo, o traba-

112 Somanlu, ano 8, n. 2, jul./dez. 2008 

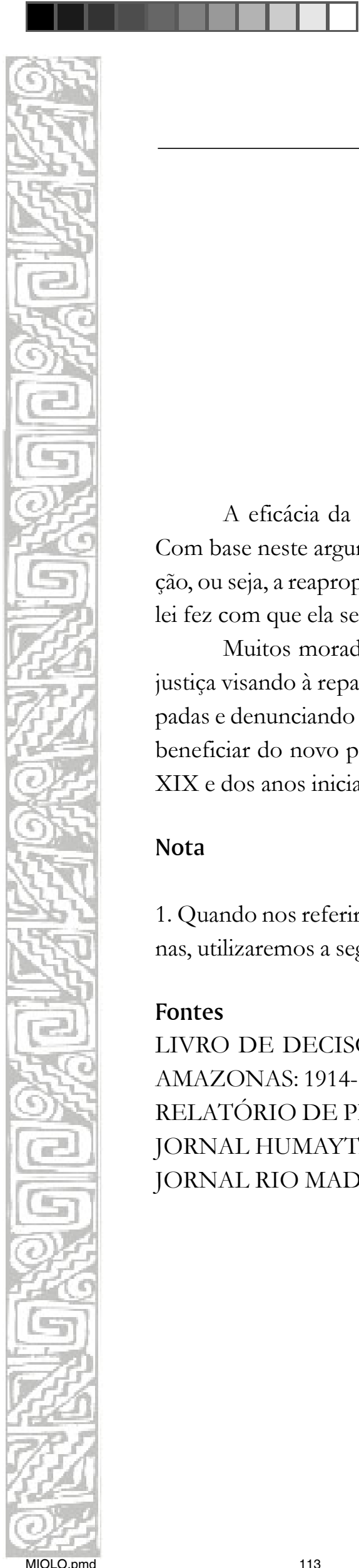

\section{Nota}

\section{Fontes} AMAZONAS: 1914-1930.

Davi Avelino Leal

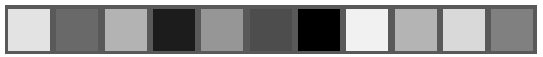

\begin{abstract}
lhador livre; o trabalhador rural com direitos comunais, o habitante sem eles; o proletário não livre, o grevista consciente de seus direitos; o diarista rural sem terras que ainda pode processar seu patrão por agressão. E se a eficácia da operação da lei em sociedades divididas em classes tem faltado repetidamente a sua própria retórica de igualdade, ainda assim a noção de domínio da lei é, em sim mesma um bem incondicional (THOMPSON, 1977, p. 358-359).
\end{abstract}

A eficácia da lei residia no fato dela parecer justa, igualitária e universal. Com base neste argumento é que se podia impor determinados limites à dominação, ou seja, a reapropriação do discurso por aqueles que se viam prejudicados pela lei fez com que ela servisse de arma para a luta (FORTES, 1995, p. 93).

Muitos moradores das inúmeras localidades do rio Madeira recorreram à justiça visando à reparação de danos, reivindicando áreas "tradicionalmente" ocupadas e denunciando os abusos do poder local, pois este procurava a todo custo se beneficiar do novo processo de territorialização característico do final do século XIX e dos anos iniciais do século XX.

1. Quando nos referirmos aos Livros de Decisões e Julgados da Justiça do Amazonas, utilizaremos a seguinte abreviação: LDJJA.

LIVRO DE DECISÕES E JULGADOS DO TRIBUNAL DE JUSTIÇA DO

RELATÓRIO DE PRESIDENTE DE PROVÍNCIA: 1870-1888.

JORNAL HUMAYTAENSE, de março de 1908 a junho de 1907. JORNAL RIO MADEIRA, janeiro a dezembro de 1918. 


\section{Referências}

CUNHA, Euclides da. Amazônia: um paraíso perdido. 3. ed. Manaus:Valer, 2003.

DEAN, Waren. A luta da borracha no Brasil. São Paulo: Nobel, 1989.

FERREIRA, Alexandre Rodrigues. Relação circunstanciada do rio Madeira e seus territórios. In: CONGRESSO BRASILEIRO DE GEOGRAFIA, 10. Anais do Rio de Janeiro: Congresso Nacional de Geografia, 1949.

FOOT HARDMAN, Francisco. Trem Fantasma: A ferrovia madeira-mamoré e a modernidade na Selva. São Paulo: Companhia das Letras, 2005.

FORTES, Alexandre. O Direito na obra de E.P. Thompson. Revista de História Social, Campinas-SP, 2, p. 89-111. 1995.

LEAL, Davi Avelino. Entre Barracões, Varadouros e Tapiris: os seringueiros e as relações de poder nos seringais do rio Madeira (1880-1930). Dissertação (Mestrado) - Manaus 2007.

OLIVEIRA, João Pacheco de. Uma Etnologia dos “Índios Misturados”? Situação Colonial, Territorialização e Fluxos Culturais. Mana: Revista de Estudos de Antropologia Social. Rio de Janeiro, 4 (1) p. 47-77, abril, 1998.

REIS, Arthur Cezar. O seringal e o seringueiro. 2. ed. rev. Manaus: Edua/Governo do Estado, 1997.

TEIXEIRA, Carlos Correa. O aviamento e o barracão na sociedade do seringal (estudo sobre a produção extrativa de borracha na Amazônia). Dissertação (Mestrado) São Paulo, 1980.

THOMPSON, E. P. Senhores e caşadores. Rio de Janeiro: Paz e Terra, 1995.

VELHO, Otávio Guilherme. Capitalismo autoritário e campesinato. Rio de Janeiro: Difel, 1979.

VIEIRA, Fabrício dos Santos. Assaltos e Escaramuças: resistência indígena na Província do Amazonas. Manaus, 2004 (Monografia de Final de Curso).

114 Somanlu, ano 8, n. 2, jul./dez. 2008 